\title{
IPTU: um estudo sobre o critério espacial da hipótese tributária
}

\author{
Cláudia Guimarães dos Santos \\ Larissa Vasconcelos Naves \\ Thays Martorelli ${ }^{1}$
}

\begin{abstract}
Resumo
A partir do estudo pormenorizado da regra matriz de incidência fiscal fez-se possível a construção daquela referente ao IPTU, tendo em vista as previsões insertas no art. 156, I da Constituição Federal - CF - e arts. 32 e 34 do Código Tributário Nacional CTN. No antecedente da norma, tem-se a hipótese tributária formada por critérios onde o critério de incidência é caracterizado pela localização do fato, ou seja, o local em que se realiza o critério material referente à propriedade, domínio útil ou posse com ânimo definitivo. 0 critério espacial enseja a análise das vicissitudes acerca da definição de zona urbana e rural e, portanto, das controvérsias entre o Imposto sobre a Propriedade Predial e Territorial Urbano - IPTU e o Imposto Territorial Rural - ITR, haja vista a incidência de ambos sobre a propriedade territorial. A determinação de zona urbana e rural cabe à norma geral, consubstanciada no CTN, uma vez que este foi recepcionado pela CF como lei complementar. Todavia, nada impede ao Município traçar algumas diretrizes neste sentido. Quanto à característica escolhida para definir se o imóvel tem natureza urbana ou rural, 0 CTN elegeu o critério da localização, enquanto o Supremo Tribunal Federal - STF entendeu aplicável o Decreto $n .057 / 66$, que elege 0 critério da destinação, em virtude de se tratar de lei posterior. Ocorre que, em que pese a tese do STF, 0 critério do CTN é que se compatibiliza com os mandamentos constitucionais e prima pela autonomia do Município, impedindo que o contribuinte escolha 0 imposto a ser pago a título de tributo.
\end{abstract}

Palavras-Chave: IPTU; Zona urbana; Competência; Destinação; Localização.

\section{Introdução}

$\mathrm{Na}$ conjuntura do sistema constitucional tributário brasileiro, garantidor da autonomia dos entes federados, 0 artigo 156, inciso I, da Magna Carta, estabelece que compete aos M unicípios instituir o Imposto sobre a Propriedade Territorial e Predial Urbana, o denominado IPTU. Em hierarquia inferior, normas nacionais e leis ordinárias tratam, outrossim, deste tributo, que, além de constituir um importante recurso financeiro aos cofres públicos municipais, é instrumento hábil a implementar a função social da

\footnotetext{
${ }^{1}$ Acadêmicas do 50 ano matutino do curso de Direito da Universidade Estadual de Londrina - UEL.
} 
propriedade no Brasil. Para a compreensão da norma tributária que se debruça sobre 0 IPTU, mister analisar, segundo as lições de Paulo de Barros Carvalho, a regra matriz de incidência fiscal do imposto em testilha.

Esta regra matriz tem como antecedente a hipótese tributária que descreve normativamente um evento e como conseqüente, a relação jurídica tributária que constitui um vínculo abstrato, oriundo da imputação normativa. Ambos os componentes da regra matriz desmembram-se em critérios identificadores, a saber, critério material, temporal e espacial (hipótese tributária); critério pessoal e quantitativo (relação jurídica tributária). Os critérios são objeto de divergências jurisprudenciais e doutrinárias significativas, todavia, cabe ao presente estudo, a análise das vicissitudes insertas no critério espacial atinente ao local do fato em que ocorre o critério material da hipótese, qual seja, a zona urbana do Município.

Estabelecida a regra-matriz de incidência do IPTU, imprescindível discorrer sobre àquela referente ao Imposto Territorial Rural, de competência da União já que o Código Tributário Nacional define o critério espacial do IPTU como a localização do imóvel, estabelecendo os requisitos para a configuração da zona urbana; e o critério espacial do ITR ligado à imóvel localizado, por exclusão, fora desta predeterminada zona. A definição de quais imóveis dentro do Município que se enquadram no contexto de zona urbana suscita questionamentos importantes, vez que acaba por atingir a própria definição do critério material tanto do IPTU, quanto do ITR.

Nessa razão, cumpre atentar sobre qual é o ente político competente para a definição do critério espacial e por qual instrumento legislativo deve ser procedido tal intento. A jurista Valéria Furlan parte destes questionamentos e estabelece possíveis respostas ligadas à competência do Município ante a autonomia legislativa do ente; à competência da União, via lei complementar; ao CTN enquanto norma nacional e, por fim, ao M unicípio, com base no zelo à função social da propriedade.

Além da referida controvérsia acerca da incidência do IPTU e ITR, outra questão a ser ventilada concerne à particularidade eleita para definir se o imóvel é urbano ou rural. Por derradeiro, o exame das legislações que dispõe sobre o critério espacial da hipótese do IPTU far-se-á imprescindível para delimitar o atual posicionamento dos tribunais superiores e da melhor doutrina sobre a solução da celeuma que o tema encerra. 


\section{Regra-matriz de incidência fiscal}

Segundo ensinamentos do doutrinador Paulo de Barros Carvalho (2007, p. 252), a norma tributária em sentido estrito é aquela que define o núcleo do tributo, ou seja, a incidência fiscal. Sua construção se apresenta com a compostura própria dos juízos hipotético-condicional, apresentando, então, uma hipótese, suposto ou antecedente, a que se conjuga um mandamento, conseqüência ou estatuição.

Assim para obter-se 0 aspecto abstrato da regra-matriz é preciso isolar seus componentes em si, como forma de estruturação daquela.

0 antecedente trará a previsão de um fato, enquanto o conseqüente prescreverá a relação jurídica que se vai instaurar quando acontecer 0 fato cogitado no suposto (CARVALHO, 2007, p. 252).

Define-se a hipótese tributária como sendo a descrição normativa de um evento que, concretizado no nível das realidades materiais e relatado no antecedente de norma individual e concreta, fará irromper o vínculo abstrato que o legislador estipulou na conseqüência (CARVALHO, 2007, p. 258).

Já a relação jurídica tributária é o vínculo abstrato, que surge pela imputação normativa, e consoante o qual uma pessoa, chamada de sujeito ativo, credor ou pretensor, tem o direito subjetivo de exigir de outra, denominada sujeito passivo ou devedor, o cumprimento de prestação de cunho patrimonial (CARVALHO, 2007, p. 300).

Tanto a hipótese como a relação jurídica tributária são constituídas por critérios identificadores, quais sejam, critério material, temporal e espacial, no que toca à hipótese, e critério pessoal e quantitativo, quanto à relação.

O critério material faz referência a um comportamento de uma pessoa e é identificado por um verbo e seu complemento.

Nos dizeres da doutrinadora Valéria Furlan $(2004$, p. 62) o aspecto material consiste no fato lícito, genérico e abstrato descrito na sua respectiva hipótese de incidência, abstratamente isolado das coordenadas de tempo e espaço.

0 critério temporal é compreendido como 0 grupo de indicações, contidas no suposto da regra, que oferecem elementos capazes de definir, com precisão, em que 
momento se deu o fato descrito. É, pois, o marco de tempo que assinala o surgimento de um direito subjetivo para o sujeito ativo e de um dever jurídico para o sujeito passivo.

o critério espacial estabelece onde ocorreu o critério material da hipótese, ou seja, 0 local do fato.

0 critério pessoal é o componente que possibilita a identificação dos sujeitos da relação - sujeito ativo, credor ou pretensor, e sujeito passivo ou devedor.

O sujeito ativo será a pessoa política possuidora de capacidade tributária ativa, ou seja, de capacidade para arrecadar tributo e fiscalizar sua arrecadação. Em regra, o ente federado que detém capacidade tributária ativa também detém competência para instituir tributo, contudo, a arrecadação poderá ser delegada a outro ente, resultando, desta forma, na não coincidência entre o sujeito tributante e aquele que arrecada, é o caso da parafiscalidade.

Quanto ao sujeito passivo, este, segundo entendimento doutrinário, será o contribuinte, o responsável - e aqui se tem a figura do sucessor - e o substituto.

Por fim, o critério quantitativo institui o objeto da prestação, que se consubstancia na base de cálculo, a qual se destina, primordialmente, a dimensionar a intensidade do comportamento inserto no núcleo do fato jurídico, e na alíquota, que se traduz em uma fração do valor da base de cálculo.

Presentes todos os componentes mencionados, possível a identificação da regramatriz de incidência.

Tendo conhecimento de conceitos tão relevantes, cabe, agora, analisar a regramatriz do Imposto sobre Propriedade Predial e Territorial Urbana - IPTU, objeto de estudo do presente artigo.

a) Regra-matriz de incidência do IPTU

Trazem os artigos 156, da Constituição Federal, e 32 a 34, do Código Tributário Nacional, os dados gerais para a construção da regra-matriz de incidência do IPTU. Assim dispõem:

Art. 156, CF: Compete aos M unicípios instituir impostos sobre:

I - propriedade predial e territorial urbana;

(...) 
$\S 1$. Sem prejuízo da progressividade no tempo a que se refere 0 art. 182, §4ㄴ, II, 0 imposto previsto no inciso I poderá ser:

I - ser progressivo em razão do valor do imóvel;

II - ter alíquotas diferentes de acordo com a localização e o uso imóvel.

(...)

Art. 32, CTN. 0 imposto, de competência dos Municípios, sobre a propriedade predial e territorial urbana tem como fato gerador a propriedade, o domínio útil ou a posse de bem imóvel por natureza ou por acessão física, como definido na lei civil, localizado na zona urbana do Município.

$\S 1$. Para os efeitos deste imposto, entende-se como zona urbana a definida em lei municipal, observado o requisito mínimo da existência de melhoramentos indicados em pelo menos dois dos incisos seguintes, construídos ou mantidos pelo Poder Público:

I - meio-fio ou calçamento, com canalização de águas pluviais;

II - abastecimento de água;

III - sistema de esgotos sanitários;

IV - rede de iluminação pública, com ou sem posteamento para distribuição domiciliar;

V - escola primária ou posto de saúde a uma distância máxima de 3 (três) quilômetros do imóvel considerado.

$\S 2$. . A lei municipal pode considerar urbanas áreas urbanizáveis, ou de expansão urbana, constantes de loteamentos aprovados pelos órgãos competentes, destinados à habitação, à industria ou ao comércio, mesmo que localizados fora das zonas definidas nos termos do parágrafo anterior.

Art. 33. A base de cálculo do imposto é o valor venal do imóvel.

Parágrafo único. Na determinação da base de cálculo, não se considera o valor dos bens móveis mantidos, em caráter permanente ou temporário, no imóvel, para efeito de sua utilização, exploração, aformoseamento ou comodidade.

Art. 34. Contribuinte do imposto é o proprietário do imóvel, o titular do seu domínio útil, ou o seu possuidor a qual quer título.

Podem-se verificar, através do exame dos supracitados artigos, todos os elementos que preenchem a regra, formando a norma tributária no caso do imposto predial e territorial urbano.

Isolemos, então, cada componente para o estudo da norma em concreto:

a) Critério material: ser proprietário de imóvel predial ou territorial; ser titular de domínio útil; ser possuidor a qualquer título de tal imóvel.

b) Critério temporal: via de regra, 10 de janeiro do ano civil.

Vale ressaltar que o Sistema Tributário Brasileiro determina como regra ser o IPTU arrecadado anualmente, ou seja, trata-se de imposto cobrável em razão do chamado ano base, tal como ocorre com o imposto de renda. Assim sendo, pode a lei municipal, conforme prevê 0 § $2^{0}$, do artigo 144, do CTN, fixar, expressamente, em que momento desse período 
se dará a concretização da hipótese de incidência do referido imposto. Em geral, os municípios definem esse momento como sendo "a propriedade existente em 1 을 de janeiro de cada ano" (PEIXOTO, 2002, p. 424).

c) Critério espacial: o imóvel deverá estar localizado na zona urbana do município.

A princípio se afirmará, conforme disposição do CTN, que o critério espacial está ligado diretamente à localização do imóvel. Contudo, lembra-se que tal afirmação é objeto de celeuma doutrinária e jurisprudencial, questão fundamental a ser discorrida no presente trabalho.

Além disso, restará definido, posteriormente, o que seja zona urbana e sua equiparação, apontada no CTN.

d) Critério pessoal:

Sujeito ativo: Município, Distrito Federal e Territórios sem municípios (acaso existam).

Sujeito passivo: qualquer pessoa, física ou jurídica, que seja proprietária plena do bem predial ou territorial, ou, quem tenha o domínio útil ou qualquer tipo de posse com ânimo, exercício ou exteriorização de tornar-se proprietário pleno (M IRANDA, 2002, p. 320).

e) Critério quantitativo:

Base de cálculo: valor venal do bem imóvel.

Alíquota: traduz-se numa fração do valor venal, donde a multiplicação desta fração pela base de calculo ensejará o quantum devido (FURLAN, 2004, p. 110). Poderá ser progressiva segundo a localização ou utilização do imóvel, bem como em relação ao tempo (art. 182, §4, II, CF).

A acepção e o alcance de vários termos definidos em lei e aqui trazidos são muito controvertidas, provocando inúmeras discussões doutrinárias e jurisprudenciais. Por isso, ater-se-á, apenas, a um destes aspectos, qual seja, o critério espacial.

Para melhor visualizar a problemática envolvendo tal critério, necessário identificar a regra-matriz de incidência do Imposto sobre Propriedade Territorial Rural, de competência da União, já que o conceito de zona rural será extraído residualmente, como se observa no art. 29 do CTN. 
a) Regra-Matriz de incidência do ITR

Para extrair a regra matriz do ITR também imprescindível a análise do texto normativo que trata deste imposto.

Dispõe o artigo 153 da Constituição Federal

Compete à União instituir impostos sobre:

(...) VI - a propriedade territorial rural;

$\S 4^{\circ} .0$ imposto previsto no inciso VI do caput:

I - será progressivo e terá suas alíquotas fixadas de forma a desestimular a manutenção de propriedades improdutivas;

II - não incidirá sobre pequenas glebas rurais, definidas em lei, quando as explore 0 proprietário que não possua outro imóvel;

III - será fiscalizado e cobrado pelos Municípios que assim optarem, na forma da lei, desde que não implique redução do imposto ou qualquer outra forma de renúncia fiscal.

O Código Tributário Nacional assim estabelece

Art. 29. 0 imposto, de competência da União, sobre a propriedade territorial rural tem como fato gerador a propriedade, o domínio útil ou a posse de imóvel por natureza, como definido na lei civil, localizado fora da zona urbana do M unicípio.

Art. 30. A base de cálculo do imposto é o valor fundiário.

Art. 31. Contribuinte do imposto é o proprietário do imóvel, o titular de domínio útil, ou seu possuidor a qualquer título.

Possível, pois, destacar cada critério constitutivo da norma jurídica tributária.

a) Critério material: ser proprietário de imóvel territorial; titular de domínio útil; ou possuidor a qualquer título.

b) Critério temporal: $1^{0}$ de janeiro do ano civil, em regra.

c) Critério espacial: imóvel deve estar localizado fora da zona urbana.

Percebe-se de imediato toda a controvérsia que pode surgir quanto à definição de zona rural, vez que esta será obtida por exclusão quando da acepção de zona urbana, trazida pelo Município.

d) Critério pessoal:

Sujeito ativo: ordinariamente será a União. Contudo, como se extrai do artigo supra da Constituição, poderá a União delegar a arrecadação e fiscalização de tal imposto aos 
M unicípios e Distrito Federal, hipótese em que estes passarão a ser o sujeito ativo da relação jurídica tributária.

Sujeito passivo: será o proprietário, detentor de domínio útil e possuir com ânimo de ser proprietário.

e) Critério quantitativo:

Base de cálculo: valor fundiário ou valor da terra nua tributável - VTNt.

Alíquota: fração do valor da terra nua, considerando, também, a área total do imóvel e o seu grau de utilização. A Constituição prevê, ainda, a utilização de alíquotas progressivas para desestimular a manutenção de propriedades improdutivas.

Passa-se, enfim, ao estudo da controvérsia envolvendo o IPTU e o ITR.

\section{Competência e instrumento para definição do critério espacial do IPTU}

Como alinhavado, tanto o IPTU, quanto o ITR incidem sobre a propriedade territorial. Assim, guardada a maior amplitude daquele, que também incide sobre a propriedade predial, mencionadas exações possuem o mesmo critério material, vale dizer, ser proprietário de bem imóvel.

Verifica-se que o traço que difere a hipótese de incidência do IPTU da hipótese do ITR, segundo o CTN, é a localização do imóvel, ou seja, o critério espacial. Isso porque, o IPTU incidirá sobre os imóveis localizados na zona urbana do Município e, por via de exclusão, sobre as propriedades territoriais localizadas fora desta zona, deverá incidir o ITR (art. 29 do (TN).

Antes de adentrar nas questões controvertidas que permeiam estes dois impostos, mister asseverar que o critério espacial da hipótese de incidência do IPTU não se confunde com o campo de eficácia da lei tributária. Com efeito, enquanto a lei tributária municipal estende sua eficácia por todo território do Município, o IPTU onera apenas os imóveis localizados dentro do perímetro urbano.

Outrossim, sendo a zona urbana o traço característico do IPTU, faz-se necessário conceituá-la. Neste desiderato, Marcelo Magalhães Peixoto (2002, p. 425), com base nos ensinamentos de Aires Fernandino Barreto, aduz: 
Nesse sentido, o professor conceitua zona urbana, como por oposição à rústica, 0 embasado na existência ou não de equipamentos. 0 referido critério demonstra que são urbanas as áreas dotadas de equipamentos que ensejam ao homem condições de habitação, trabalho, educação, segurança, assistência, circulação, recreação.

Para Hely Lopes M eirelles (2008, p. 556), a delimitação da zona urbana, para fins de incidência do IPTU, compete ao Município, o qual deverá definir, por meio de lei, os requisitos que darão à área condição de urbana ou urbanizável, ainda segundo o autor, é conveniente que tais requisitos coincidam com as exigências estabelecidas pelo artigo 32 , 10 , do CTN.

Observa-se, todavia, que a competência municipal para definir o que seja a zona urbana não é aceita de forma unânime pela doutrina, vez que a delimitação de urbano, necessariamente, implica na definição do que é rural, o que refletirá na incidência do ITR, que como demonstrado, é um imposto da União.

A determinação de tais aspectos (urbano e rural) constitui-se, pois, na própria definição do critério material do antecedente normativo tanto do IPTU, quanto do ITR. Sob esta perspectiva, há de se perquirir quem então seria a pessoa política competente para estabelecer referidos aspectos e, ainda, através de qual instrumento legislativo, vale dizer, lei complementar (norma nacional) ou lei ordinária.

Partindo de tais questionamentos, Valéria Furlan (2004, p. 58) apresenta quatro possíveis respostas. A primeira, com fundamento no princípio da autonomia política dos entes federados, propõe que para a definição de zona urbana, para fins de IPTU, seja competente o Município, assim como compete à União, por meio de lei ordinária, a definição de zona rural.

Refutando tal hipótese, a autora adverte que tamanha autonomia legislativa fatalmente ensejaria conflito de competência entre a União e o Município, eis que este ao delimitar a zona urbana, estaria ao mesmo tempo, por exclusão, delimitando zona rural, matéria que extrapola sua competência. 0 mesmo raciocínio aplica-se à União, quando fosse definir zona rural.

Uma segunda hipótese seria a União, mediante lei complementar, definir o que seja zona urbana e zona rural. De acordo com Valéria Furlan (2004, p. 59), a presente hipótese deve ser prontamente rechaçada, eis que contraria a competência e autonomia legislativa 
das pessoas políticas de direito público, "incabível seria atribuir à lei complementar a tarefa de definir cabalmente 0 que seja zona urbana e rural a pretexto de prevenir eventuais conflitos de competência".

$\mathrm{Na}$ terceira hipótese, à União, por meio de lei complementar, caberia traçar os critérios a serem observados para a definição de zona rural e urbana, na forma como estabelecido pelo CTN em seus artigos 29 e 32.

A mencionada autora também discorda desta hipótese, utilizando-se, para tanto, dos seguintes argumentos. 0 artigo 29 do CTN ao estabelecer, para fins de incidência do ITR, o critério da localização do imóvel, está atribuindo ao Município a competência exclusiva para definir a zona urbana e, por via de conseqüência, a zona rural.

No tocante ao artigo 32 do CTN que estabelece como critérios a localização e o número de equipamentos $\left(\S 1^{\circ}\right.$ ) , afirma a autora, que tais critérios só seriam eficientes se fossem estabelecidos por cada M unicípio, conforme sua realidade.

Com efeito, os critérios de equipamentos urbanos, da situação ou destinação do imóvel, seriam eficientes, sim, mas desde que estabelecidos pela própria lei municipal, pois somente cada Município, no exercício da sua competência legislativa para definir a área urbana, teria condições de legislar de acordo com suas peculiaridades locais. (2004, p. 60)

Segundo o entendimento da aludida jurista, o CTN, ao definir tais critérios, extrapolou sua competência e invadiu a dos M unicípios.

Por fim, na quarta hipótese o M unicípio é competente para definir as zonas urbanas e rurais, não só para fins de IPTU e ITR, mas, principalmente, para zelar pelo fiel cumprimento da função social da propriedade urbana, como estabelecido no artigo 182 da Constituição Federal de 1988.

Esta é, segundo o entendimento de Valéria Furlan, a hipótese mais aceitável, eis que exsurge de uma interpretação sistemática da Constituição. Isso porque, o legislador constituinte, além de conferir ao M unicípio a competência de delinear todos os critérios da hipótese de incidência do IPTU, impôs a este, nos termos do artigo 182, o dever de executar a política de desenvolvimento urbano, a fim de ordenar o pleno desenvolvimento das funções sociais da cidade e garantir o bem estar de seus habitantes. 
Assevera-se que a política de desenvolvimento urbano é instrumentalizada pelo plano diretor aprovado pela Câmara Municipal, o qual ordenará exigências que deverão ser atendidas para que a propriedade urbana cumpra sua função social ( $\S \S 1$ e $2^{\circ}$ do art. 182 da CF/88). Nesse sentido, conclui a autora (FURLAN, 2004, p. 61):

Logo, não há campo para maiores lucubrações doutrinárias no intuito de esclarecer qual a pessoa política competente para traçar as fronteiras da área urbana e rural. Compete, pois, apenas ao Município traçar os limites da área urbana, sob seus próprios critérios, para que possa assegurar a observância do princípio da função social da propriedade urbana e, por via de conseqüência, para fins de tributação, já que, por expressa disposição constitucional, é dever do legislador municipal utilizar-se do IPTU como instrumento de política de desenvolvimento e de expansão urbana.

Data venia, em que pesem tais argumentos, verifica-se que deixar ao alvedrio de cada Município, de acordo com suas particularidades, a livre definição de zona urbana e rural ensejaria o enfraquecimento do pacto federativo. Com efeito, quando a Constituição Federal atribui a cada pessoa política competência tributária, tem por objetivo garantir a estas autonomia política e financeira, contudo, referida autonomia, embora deva ser respeitada, não pode ser tida como absoluta, mormente, quando confronta com princípios fundamentais para o Estado brasileiro, como o caso do princípio federativo.

O sistema jurídico tributário brasileiro foi constituído de forma a proteger e fortalecer o pacto federativo, observando-se, assim, a seguinte estrutura piramidal: no topo a Constituição Federal delimitando a competência de cada ente federado, bem como estabelecendo princípios a serem observados; abaixo, encontra-se a norma nacional (geral), que deve ser veiculada através de lei complementar e, cujo objetivo primordial é dispor sobre conflitos de competência entre os entes federados; em seguida e no mesmo patamar, encontram-se as normas federais, as normas estaduais, as normas distritais e as normas municipais, que têm por finalidade a instituição dos tributos respectivos de cada ente.

Ressalta-se que o CTN foi recepcionado pela Constituição Federal com status de lei complementar, haja vista seu conteúdo de norma geral. Nesse vértice, estando entre suas funções dispor sobre conflitos de competência, a exemplo do que ocorre entre a União e o M unicípio, no que se refere ao ITR e ao IPTU, desume-se ser constitucional a norma prevista no seu artigo 32, § 1‥ A esse respeito, aduz M arcelo M agalhães Peixoto (2002, p. 426): 
Ora, se cabe à Lei Complementar dispor sobre os conflitos de competência, a norma do CTN deriva da Constituição Federal. 0 artigo $32 \S 1$ o do CTN, o legislador complementar não extrapolou seus poderes, ao contrário, cumpriu um mandamento constitucional, preencheu a lacuna so bre esse tema. Note-se que, se assim não o fizesse, teria persistido o conflito de competência e a tributação da propriedade territorial, quer urbana, quer rural, careceria de segurança jurídica.

Do exposto, conclui-se que tanto a União, quanto o Município deve observar o disposto na norma geral, a fim de que possa ser protegida a própria Federação. Assim, cabe à lei complementar a definição prévia de critérios a serem observados para a incidência do IPTU e, conseqüentemente, do ITR.

Cumpre observar, também, que a observância dos critérios estabelecidos pelo CTN não impede o Município de executar sua política de desenvolvimento urbano, até porque, 0 $\S 2$ do artigo 32 do CTN prevê a possibilidade de expansão urbana conforme a vontade e a necessidade do Município.

\section{Critério espacial do IPTU: localização ou destinação?}

Outra questão controvertida acerca da incidência do IPTU e do ITR refere-se à característica escolhida para definir se o imóvel tem natureza urbana ou rural. Como já demonstrado, o CTN elegeu a localização do imóvel como critério definidor de sua natureza (art. 29).

Contudo, verifica-se que outras espécies de instrumentos normativos dispuseram de forma diferente sobre a delimitação de propriedade rural e urbana, o que gerou um dissenso doutrinário e jurisprudencial. Para uma melhor compreensão dessa divergência, cumpre demonstrar o teor de referidos instrumentos normativos.

Dispondo sobre o Estatuto da Terra, a Lei ordinária federal ำ 4.504/64, em seu artigo 4, I traz o conceito de imóvel rural como sendo o prédio rústico de área contínua, qualquer que seja sua localização, que se destine à exploração extrativista agrícola, pecuária ou agroindustrial. Da análise de tal dispositivo, infere-se que o critério escolhido pelo legislador para definir imóvel rural e, por via de conseqüência, o imóvel urbano, foi a destinação da propriedade. 
Em 25 de outubro de 1966 foi decretada a Lei no 5.172 (CTN), que como aduzido passa a considerar a localização do imóvel como critério determinante para a definição de urbano e rural.

Todavia, em 18 de novembro de 1966 foi editado o Decreto-lei no 57, cujos artigos 14, 15 e $16^{2}$ voltaram a adotar, para fins de incidência do IPTU e do ITR, o critério da destinação do imóvel, independentemente de sua localização. Com efeito, estabelece o artigo 14 do mencionado decreto, que incide IPTU sobre a propriedade localizada na zona rural, que seja utilizada como sítio de recreio e cuja eventual produção não se destine ao comércio.

0 artigo 15, por sua vez, determina a incidência de ITR sobre os imóveis localizados na zona urbana, cuja utilização esteja voltada para a exploração extrativa vegetal, agrícola, pecuária ou agroindustrial.

Em 1972, a Lei ordinária federal no 5.868, que instituiu o Sistema Nacional de Cadastro Rural, elegeu dois critérios definidores do imóvel rural, quais sejam a destinação e o tamanho do imóvel. Assim, segundo o artigo 60 da aludida lei federal, considera-se imóvel rural aquele que se destinar à exploração agrícola, pecuária, extrativa vegetal ou agroindustrial e que, independentemente de sua localização, tiver área superior a 1 (um) hectare. Arremata o parágrafo único do sobredito artigo, que os demais imóveis estão sujeitos à incidência do IPTU, qualquer que seja sua localização.

Nota-se que os artigos 29 e 32 do CTN foram, em tese, alterados pelo Decreto-lei no 57/66, tendo tal revogação, à época, sido aceita pela doutrina e pela jurisprudência. Com o advento da Emenda Constitucional no 1/69, referido decreto, por tratar de normas gerais, assim como o próprio CTN, passou a ter status de lei complementar. Dessa forma, o artigo 6ำ, parágrafo único da Lei ordinária federal no 5.868/72, ao adotar um novo critério

\footnotetext{
2 "Art. 14. 0 disposto no art. 29 da Lei n. 5.172, de 25 de outubro de 1966, não abrange o imóvel que, comprovadamente, seja utilizado como sítio de recreio e no qual a eventual produção não se destine ao comércio, incidindo assim, sobre o mesmo, o Imposto sobre a Propriedade Predial e Territorial Urbana, a que se refere 0 art. 32 da mesma Lei."

"Art. 15. 0 disposto no art. 32 da Lei n. 5.172, de 25 de outubro de 1966, não abrange o imóvel que, comprovadamente, seja utilizado em exploração extrativa vegetal, agrícola, pecuária ou agroindustrial, incidindo assim, sobre o mesmo, o ITR e demais tributos com o mesmo cobrados."

"Art. 16. Os loteamentos das áreas situadas fora da zona urbana, referidos no $§ 2^{\circ}$ do art. 32 da Lei n. 5.172, de 25 de outubro de 1966, só serão permitidos quando atendidos o disposto no art. 61 da Lei n. 4.504, de 30 de novembro de 1964."
} 
(tamanho da área) na definição de imóvel rural, alterou disposições de norma hierarquicamente superior, o que não era admitido.

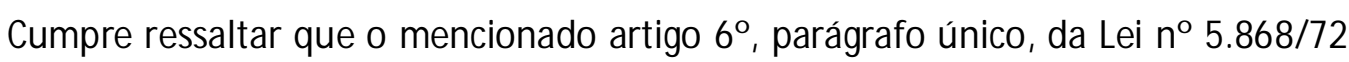
foi, num primeiro momento, considerado inconstitucional pelo STF, contudo, após o Senado baixar a Resolução, a Suprema Corte voltou atrás e reconheceu a constitucionalidade do aludido artigo, assim como de seu respectivo parágrafo.

Atualmente, os doutrinadores divergem quanto a qual norma geral (CTN ou Decreto-lei 57/66) deve ser observada para fins de incidência de IPTU e ITR, ou seja, qual critério deve ser adotado na definição de imóvel urbano e rural, haja vista que as referidas normas foram, conforme posicionamento do $\mathrm{STF}^{3}$, recepcionadas pela Constituição Federal de 1988.

A esse respeito, a jurisprudência do Superior Tribunal de Justiça tem se posicionado pela aplicação do disposto no Decreto-lei, consoante se infere da seguinte decisão:

TRIBUTÁRIO. IMÓVEL NA ÁREA URBANA. DESTINAÇÃO RURAL. IPTU. NÃOINCIDÊNCIA. ART. 15 DO DL 57/1966. RECURSO REPETITIVO. ART. 543-C DO CPC.

1. Não incide IPTU, mas ITR, sobre imóvel localizado na área urbana do M unicípio, desde que comprovadamente utilizado em exploração extrativa, vegetal, agrícola, pecuária ou agroindustrial (art. 15 do DL 57/1966).

2. Recurso Especial provido. Acórdão sujeito ao regime do art. 543-C do CPC e da Resolução 8/2008 do ST). (REsp 1112646/SP, Rel. Ministro HERMAN BENJAMIN, PRIM EIRA SEÇÃO, julgado em 26/08/2009, DJe 28/08/2009)

Observa-se que aludido posicionamento fundamenta-se no princípio hermenêutico de solução de conflitos entre normas de mesma hierarquia, segundo qual, norma posterior revoga norma anterior, ou seja, o Decreto-lei no 57/66 por ser posterior derrogou os artigos 29 e 32 do CTN.

A doutrina majoritária, entretanto, entende que o critério a ser adotado é 0 estabelecido pelo CTN, vale dizer, a localização do imóvel. Na defesa desse entendimento, alega-se que a competência tributária atribuída pela Constituição não pode ser alterada por nenhuma norma infraconstitucional, muito menos pelos contribuintes. Nesse sentido, são os ensinamentos de Roque Antonio Carraza (2008, p. 655):

\footnotetext{
${ }^{3}$ Recurso Extraordinário № 140773/SP.
} 
Possivelmente sem se darem conta disso, sufragam a errônea idéia de que a vontade do contribuinte pode alterar competências tributárias os que entendem que é a "destinação" (rural ou urbana) do imóvel que determina a incidência do IPTU (imposto de competência municipal) ou do ITR (imposto de competência federal), não importando se o bem está localizado na zona urbana ou na zona rural do M unicípio. A nosso juízo, se o imóvel está situado na zona urbana do M unicípio, o imposto devido, por seu proprietário, é o IPTU; se na zona rural, o ITR, absolutamente não importando se sua destinação é urbana ou rural.

Em que pese mencionado posicionamento jurisprudencial, o entendimento que deve prevalecer é o que adota o critério da localização do imóvel, eis que revela ser mais compatível com os mandamentos da Constituição Federal. De fato, quando o constituinte atribuiu ao Município a competência para tributar a propriedade urbana, a interpretação que se apresenta mais lógica é que o vocábulo urbana refere-se ao critério espacial do imposto, ou seja, o local em que ocorre o critério material da hipótese.

Nesse vértice, com fundamento na Constituição, o critério que deve ser adotado na definição de imóvel urbano e, conseqüentemente, rural é o da localização. Assim, os imóveis localizados dentro da zona urbana do Município, cuja definição desta encontra-se previamente estabelecida nos $\S \S 1^{\circ}$ e e $2^{\circ}$ do artigo 32 do CTN, devem ser gravados pelo IPTU, independentemente de suas destinações.

\section{Conclusão}

A partir do estudo pormenorizado da regra matriz de incidência fiscal fez-se possível a construção daquela referente ao IPTU, tendo em vista a combinação dos dados insertos no art. 156, I da CF e arts. 32 e 34 do CTN. Nesse viés, constata-se que no antecedente da norma abstrata e geral está a hipótese de incidência subdividida em critérios. 0 primeiro deles é o critério material que revela o comportamento de uma pessoa passível de identificação por meio do verbo e seu complemento, portanto, ser proprietário de imóvel predial ou territorial; ser titular do domínio útil e ser possuidor a qualquer título de imóvel ensejam a cobrança do tributo. Subseqüentemente, tem-se o critério temporal que atine ao momento em que se deu o fato descrito, via de regra é 0 10 de janeiro do ano civil. 0 critério espacial, objeto central do presente artigo, é definido pelo local do fato, qual seja, a zona urbana do Município. 
No conseqüente da norma observa-se a relação jurídica tributária formada pelo critério pessoal e quantitativo. No primeiro, figura-se como sujeito ativo, o M unicípio e como sujeito passivo aqueles que realizam o critério material da hipótese, ressaltando-se que no caso da posse o contribuinte é apenas aquele que detém ânimo de domínio sobre o imóvel. No que tange ao segundo, a base de cálculo é formada pelo valor venal do bem imóvel e a alíquota pela fração deste valor.

Estabelecidos os critérios da regra matriz do IPTU tornou-se compreensível a análise das vicissitudes acerca da definição de zona urbana e rural e critério de incidência do IPTU, que como visto, pode ser estabelecido pela localização ou destinação em face das controvérsias da legislação sobre o tema. Apesar das semelhanças entre IPTU e ITR, haja vista que ambos incidem sobre a propriedade territorial, cumpre ressaltar que, segundo 0 CTN, o traço distintivo importante é a localização do imóvel, ou seja, seu critério espacial.

O IPTU incide sobre a zona urbana e o ITR, por exclusão, sobre a zona rural, consoante art. 29 do CTN. A determinação destes aspectos é de suma importância na medida em que define o próprio critério material dos dois impostos e por isso, Valéria Furlan, constrói quatro possibilidades existentes neste âmbito. Todas elas encontram óbices marcantes, quer seja na exacerbada autonomia do Município - que ao delimitar zona rural, por exclusão extrapolaria sua competência - ou porque haveria violação à autonomia do M unicípio enquanto ente federado caso coubesse à União, por lei complementar, definir as zonas ou estabelecer critérios para a definição.

Para a jurista, a solução estaria na competência do Município em estabelecer zona urbana e rural para fins de IPTU e ITR e, mormente para zelar o cumprimento da função social da propriedade urbana. Ocorre que, a despeito das possibilidades examinadas, ressalvou-se a importância de se fortalecer o pacto federativo, observando a delimitação de competência da Magna Carta, seus princípios e a hierarquia das normas. 0 CTN, nesta perspectiva, foi recepcionado pela CF como lei complementar, vez que seu conteúdo é de norma geral, assim, cabe à lei complementar definir os critérios para incidência do IPTU e via de conseqüência, do ITR. Todavia, nada impede o Município de executar sua política de desenvolvimento urbano como prevê 0 art. 32, parágrafo $2^{\circ}$ do CTN.

Quanto à característica escolhida para definir se o imóvel tem natureza urbana ou rural, o CTN (art. 29) elegeu o critério da localização do imóvel, entretanto, outros 
instrumentos normativos cuidam de outro critério, o da destinação do imóvel. 0 Estatuto da Terra (Lei ordinária federal n. 4.504/64) e o Decreto-lei n. 57/66, que sobreveio logo após o CTN, dispõem que independentemente da localização do imóvel, a destinação da propriedade é que proporciona a incidência do IPTU. A Lei ordinária federal n. 5868/72 também previa o critério da destinação, mas adicionou outro critério, o tamanho da área do imóvel.

Hodiernamente, o posicionamento do STJ e STF é pela aplicação do Decreto-lei n. 57/66, em face do princípio hermenêutico de solução dos conflitos entre normas de mesma hierarquia, ou seja, norma posterior derroga anterior. Contudo, observou-se de forma concludente que o critério da localização previsto pelo CTN compatibiliza-se mais fielmente aos mandamentos constitucionais, já que quando foi estabelecida a competência do Município para instituir imposto sobre o IPTU, a CF com o uso do vocábulo propriedade urbana, referiu-se ao critério espacial da hipótese como sendo o da localização. Deste modo, preservando a autonomia do M unicípio, ao contribuinte não cabe a escolha do imposto a ser pago a título de propriedade territorial.

\section{Referências}

TALIBA, Geraldo. Hipótese de incidência tributária. 6. ed. São Paulo: Malheiros, 2003.

CARRAZZA, Roque Antonio. Curso de direito constitucional tributário. 24. ed. São Paulo:Editora Malheiros, 2008.

CARVALHO, Paulo de Barros. Curso de direito tributário. 18. ed. São Paulo: Saraiva, 2007.

FURLAN, Valéria. Imposto Predial Territorial Urbano. 2. ed. São Paulo:Editora M alheiros, 2004.

HARADA, Kiyoshi. Imóvel cultivado em zona urbana. IPTU, ITR ou incentivo fiscal?. Jus Navigandi, Teresina, v. 11, n. 1492, 2 ago. 2007. Disponível em:

বttp://jus2.uol.com.br/doutrina/texto.asp?id=10223>. Acesso em: 19 nov. 2009.

M EIRELLES, Hely Lopes. Direito M unicipal Brasileiro. 16. ed. São Paulo: Editora M alheiros, 2008.

M IRANDA, João Damasceno Borges de. A regra-matriz do IPTU e sua Constitucionalidade. In: PEIXOTO, M arcelo Magalhães (Coord.). IPTU: Aspectos jurídicos relevantes. São Paulo: Quartier Latin, 2002. 
PEIXOTO, M arcelo M agalhães. A regra-matriz de incidência tributária do Imposto sobre Propriedade Predial e Territorial Urbana - IPTU. In: PEIXOTO, Marcelo Magalhães (Coord.). IPTU: Aspectos jurídicos relevantes. São Paulo: Quartier Latin, 2002. 